\title{
EXORDIAL, A PEÇA ESSENCIAL AO EXERCÍCIO DA JURISDIÇÃO - ASPECTOS JURÍDICOS REMANESCENTES AO DIREITO FUNDAMENTAL À PONDERAÇÃO DOS CONFLITOS PARTICULARES PARA COM O ESTADO COMO ULTIMA RATIO JURISDICIONAL
}

\author{
EXORDIAL, THE ESSENTIAL PART TO THE EXERCISE OF JURISDICTION - \\ LEGAL ASPECTS REMAINING TO THE FUNDAMENTAL RIGHT TO THE \\ CONSIDERATION OF PARTICULAR CONFLICTS WITH THE STATE AS THE \\ LAST JURISDICTIONAL RATIO
}

\begin{abstract}
Alexia Aqueni Bernardes de Oliveira ${ }^{1}$
RESUMO: O presente artigo busca apresentar a petição inicial de forma mais complexa do que sua conceituação habitual, demonstrando sua representação extraordinária para o andamento do aparato estatal jurisdicional frente a lide controvertida. Como será evidenciado esta peça formal além de romper a inércia do órgão equidistante também é a manifestação material de diversas garantias constitucionais, proporcionando aos particulares e até entidades públicas as garantias de suas pretensões não alcançadas pelas vias consensuais, ademais esta é responsável por todo o desenvolvimento processual nos órgãos do judiciário. De tal modo, visto sua importância, a própria será esmiuçada sobre os institutos jurídicos apresentados adiante neste artigo.
\end{abstract}

Palavras-chave: Petição inicial. Direito de ação. Processo. Jurisdição. Lide.

ABSTRACT: This article seeks to present the initial petition in a more complex way than its usuais conceptualization, demonstrating its extraordinary representation for the progress of the jurisdictional state apparatus in the face of the controversial dispute. As it will be evidenced this formal piece besides breaking the inertia of the equidistant organ is also the material manifestation of several constitutional guarantees, providing to individuals and even public entities the guarantees of their pretensions not reached through the consensual ways, in addition this is responsible for all the development procedural in the judicial bodies. In such a way, given its importance, it will be scrutinized on the legal institutes presented later in this article.

Keywords: Initial petition. Right of action. Process. Jurisdiction. Cope.

\footnotetext{
I Graduanda do curso de Direito pela instituição CESA (Centro de Estudos Superiores Aprendiz), autora de artigos jurídicos publicados em períodicos digitais, palestrante do Congresso Internacional Interdisciplinar de Direitos Humanos e Fundamentais, promovido pelo Conselho de Altos Estudos em Direito com o tema "Contratações públicas, prestação do serviço público e dispensa emergencial de legalidade: legalidade x interesse público" e aluna do curso "Love as a force for social Justice" promovido pela plataforma digital da Universidade de Stanford- Estados Unidos. E-mail: alexiaaqueni7@gmail.com.
} 


\section{INTRODUÇÃO}

A capacidade da sociedade humana de julgar determinados fatos baseando-se em postulados supraindividuais vem sendo perpetrada desde os primórdios da coletividade organizada. Tal juízo provém de aspectos teológicos, morais, éticos e justos provenientes de convenções firmadas entre os grupos sociais ao longo de toda história.

Ao citar o direito processual dentro deste contexto é possível verificar seu papel primordial e indispensável para a concretização deste poder-dever inserido no Estado moderno e exercido pelo próprio.

\subsection{JURISDIÇÃO, O MONOPÓLIO DA JUSTIÇA}

O Estado Democrático de Direito, atual, conta com seu neoconstitucionalismo firmado na Constituição de 1988, que, em seu artigo quinto, inciso trinta e cinco ${ }^{2}$, assegura o direito fundamental à ação. O legislador brasileiro ao inserir esta garantia no ordenamento jurídico visou alcançar o sistema de multiportas, como apregoa Elpídio Donizetti ${ }^{3}$ cuja jurisdição é invocada como ultima ratio, visto que a autocomposição não foi suficiente para solução da lide privada, consequentemente, oportuniza-se ao particular lesado provocá-la frente ao órgão público competente para intervir em sua relação fática/jurídica.

A jurisdição, juris dictio, é exercida pelo Estado de modo em que sua atividade se apresente primordialmente inerte frente aos conflitos, destarte bem diz o princípio da inércia "procedat judex ex officio", isto é, não se pode o juiz dar início ao processo de ofício, artigo I4I do $\mathrm{CPC}^{4}$, e, de igual modo, o princípio da iniciativa das partes, "nemo judex sine actore", no qual não há juiz se não haver autor que o impulsione, artigo $2^{\circ}$ do CPC. ${ }^{5}$

A inércia é rompida quando se instaura o processo, com o protocolo da petição inicial à secretária da comarca. A petição inicial, aqui tratada, é considerada pela doutrina

\footnotetext{
2 "A lei não excluirá da apreciação do Poder Judiciário lesão ou ameaça a direito" (art. 5º, XXXV da CFRB)

${ }^{3}$ DONIZETTI, Elpídio. Curso Didático de Direito Processual Civil. 22. Ed. São Paulo: Atlas, 202o, p. 203.

4 "O juiz decidirá o mérito nos limites propostos pelas partes, sendo-lhe vedado conhecer de questões não suscitadas a cujo respeito a lei exige iniciativa da parte" (art. I4I do CPC)

5 "O processo começa por iniciativa da parte e se desenvolve por impulso oficial, salvo as exceções previstas em lei” (art. $2^{\circ}$ do NCPC)
} 
majoritariamente como a peça/ato inaugural do processo. Além do exposto, com vistas, a exordial, o juiz equidistante se torna um terceiro "alheio" àquela situação material controvertida conhecendo, portanto, da pretensão e de suas proporções subjetivas e objetivas.

Ademais, o direito a petição também é assegurado pela Constituição da República Federativa do Brasil- CRFB, em seu artigo 5을 inciso XXXIV, alínea "a".

Este monopólio da justiça que se concentra sob os poderes estatais é fruto de comentários, inclusive, de Humberto Theodoro Júnior, que expõe o seguinte pensamento:

Ao vetar o indivíduo de fazer justiça pelas próprias mãos e ao assumir a jurisdição, o Estado não só se encarregou da tutela jurídica dos direitos subjetivos, como se obrigou a prestá-la sempre que regularmente invocada, estabelecendo, de tal arte, em favor do interessado, a faculdade de requerer sua intervenção sempre que se julgue lesado ou ameaçado em seus direitos ${ }^{7}$

Este impulso formal do indivíduo para com o poder estatal será o objeto abordado por este estudo, não em sua totalidade, mas no que se refere a sua conceituação de forma amplamente abrangida pelos postulados jurídicos aqui destacados, sendo este o ato que apresenta a demanda e impõe limites ao campo de atuação do juízo, pressuposto abordado também por outro princípio, o da adstrição da sentença ao pedido ${ }^{8}$, vetando o chamado litis contestatio.

O ato jurídico formal em comento, conhecido como petição inicial, peça inaugural, de ingresso, exordial, pórtica, preambular, prefacial, isagógica, autoral, vestibular... dentre várias outras nomenclaturas, está presente tanto no procedimento comum como no procedimento especial, obviamente cada um com seus requisitos genéricos e demais específicos necessitados pela natureza de cada ação. Como ulteriormente mencionado o procedimento especial possui suas peculiaridades, porém não difere muito da regra geral, sendo estas somente em pequenos pontos. Oportuno mencionar ainda que a supracitada exordial da início a fase postulatória dos procedimentos em comento.

\footnotetext{
6 "São a todos assegurados, independentemente do pagamento de taxas: a) o direito de petição aos Poderes Públicos em defesa de direitos ou contra ilegalidade ou abuso de poder...” (art. 5ำ XXXIV, “a”, da CFRB)

7 JÚNIOR, Humberto Theodoro. Curso de Direito Processual Civil - Volume I. 59. ed. Rio de Janeiro: Forense, 2018, v. I, p. 153 .

8 "É vedado ao juiz proferir decisão de natureza diversa da pedida, bem como condenar a parte em quantidade superior ou em objeto diverso do que lhe foi demandado" (art. 492 do NCPC)
} 


\subsection{PETIÇÃO INICIAL: SINGULARIDADES FORA DO PROCEDIMENTO COMUM}

É de comum notoriedade que a peça preambular detém sua matéria de modo geral regulada em capítulo próprio pela parte especial do Novo Código de Processo Civil- NCPC, e, aplica-se habitualmente estas disposições ao procedimento comum. Da mesma forma a exteriorizada demanda da início a todos os procedimentos, e não somente ao ritual ordinário, vide artigo 3189 . Subsidiariamente estes regramentos são aplicados também aos procedimentos especiais e processos de execução com suas requisições específicas.

Embora sua formalidade seja algo exigido pelo novo NCPC sob pena de indeferimento, algumas petições iniciais de outros procedimentos, que não o comum, são revestidas do princípio da instrumentalidade das formas, consequentemente, podem ser elaboradas inclusive de forma oral em audiências e sem o acompanhamento do advogado em certas situações.

Os Juizados Especiais Cíveis da Lei 9099/95 e processos trabalhistas são os exemplos mais utilizados pela doutrina na atualidade.

O artigo I4 da Lei supracitada explícita uma menor exigibilidade de requisitos formais para a instauração da pretensão particular frente ao órgão público, peculiaridade que se apresenta também aos procedimentos trabalhistas conforme o artigo 840 da Consolidação das Leis Trabalhistas (Decreto-Lei 5.452/43).

De igual forma cada ação dos procedimentos especiais também há de possuir especificações distintas a regra, como exemplificação é possível verificar logo no início dos rituais especiais do NCPC, em seu artigo 542, onde impõe requisitos especiais aplicáveis a peça inaugural para a ação de consignação em pagamento.

Dentre outras considerações é primordial ressaltar, o modus faciendi do demandante para com a exordial sempre que haver alguma especificação será explicitado pela legislação,

\footnotetext{
9 "Aplica-se a todas as causas o procedimento comum, salvo disposição em contrário deste Código ou lei. Parágrafo Único. O procedimento comum aplica-se subsidiariamente aos demais procedimentos especiais e ao processo de execução" (art.318 do NCPC)
} 
salvo, será formulada perante as requisições dos artigos 319 e 320 do NCPC, que novamente explicitando, constituem a "regra" aplicada à exordial.

\section{4.o ESSENCIALIDADE AO PROCESSO COGNITIVO}

É plausível asseverar que a exordial como exteriorização material do processo e pressuposto essencial à existência do próprio, é um ato extremamente importante para toda a marcha processual, prova disto é que, caso ela não cumpra seus requisitos vigentes nos artigos 319 e 320 do CPC, será indeferida por não conter os elementos necessários que sustentem o desenvolvimento do processo no decorrer da cognição.

Por ser uma peça vinculada diretamente ao direito público subjetivo à ação, a petição inicial além de observar todos os requisitos legais deve também vislumbrar seus aspectos linguísticos de forma concisa, pois são estes que levarão a interpretação precisa do órgão julgador para com o conflito transferido ao ato super partes, podendo esta ser explícita e até implícita com a presença dos chamados consectários legais.

É composta por princípios e normas jurídicas que norteiam a atividade democrática, fazendo assim que seus aspectos permeiem sobre todo o processo. Todos seus elementos, como, juízo competente indicado, partes com suas devidas qualificações, fatos (causa de pedir próxima) que espelham o mundo natural, fundamentos (causa de pedir remota) que "encaixam" os institutos normativos ao mundo fático, o pedido, o qual elenca as pretensões processuais (imediatas) e matérias (mediatas), o valor da causa certo e determinado (genérico é plausível quando não é possível sua determinação ou em causas de valor inestimável), as provas que se pretende produzir ao longo do processo mesmo que expostas genericamente, e dentre vários outros formalizam este ato solene, vide observância do princípios da legalidade dos atos processuais como regra.

Retoma-se que a petição inicial perante os procedimentos é deveras similar, salvo no procedimento especial, cujo este difere no que tange as requisições aplicáveis a esta.

\section{5.o CONSIDERAÇÕES FINAIS}

De forma a concluir este estudo ressalta-se uma importante premissa, a qual ratifica que, este direito do demandante à ação frente ao processo sincrético em sua fase cognitiva é manifestado pela peça preambular como já explicitado, todavia esta não esgota aquele, sendo a exordial somente sua primeira manifestação no processo, atestado pelos seguintes ensinamentos de Alexandre Freitas Câmara: 
[...] o direito de ação não se esgota no momento em que a parte pratica seu primeiro ato destinado a postular tutela jurisdicional. Exerce-se o direito de ação ao longo de todo o processo $[. .].]^{\prime \prime}$

\section{REFERÊNCIAS}

CÂMARA, Alexandre Freitas. O Novo Processo Civil Brasileiro. 5. Ed. São Paulo: Atlas, 2019.

DONIZETTE, Elpídio. Curso Didático de Direito Processual Civil. 22. Ed. São Paulo: Atlas, 2020.

JÚNIOR, Humberto Theodoro. Curso de Direito Processual Civil - Vol.r. 59. Ed. Rio de Janeiro: Forense, 2018.

${ }^{10}$ CÂMARA, Alexandre Freitas. O Novo Processo Civil Brasileiro. 5. Ed. São Paulo: Atlas, 2019. p.72. 